\title{
Pancreas transplantation: an overview
}

\author{
Atualização no transplante de pâncreas \\ Andre Ibrahim David ${ }^{1}$, Ben-Hur Ferraz-Neto ${ }^{2}$, Fernando Levino ${ }^{3}$, Roberto Ferreira Meirelles Junior ${ }^{4}$, \\ Álvaro Pacheco e Silva Filho ${ }^{5}$
}

\begin{abstract}
Pancreas transplantation is the only treatment able to reestablish normal glucose and glycated hemoglobin levels in insulin-dependent diabetic patients without the use of exogenous insulin. The evolution of pancreas transplantation in treatment of diabetes was determined by advances in the fields of surgical technique, organ preservation and immunosuppressants. The main complication leading to graft loss is technical failure followed by acute or chronic rejection. Technical failure means graft loss within the first three months following transplantation due to vascular thrombosis $(50 \%)$, pancreatitis $(20 \%)$, infection $(18 \%)$, fistula $(6.5 \%)$ and bleeding $(2.4 \%)$. Immunological complications still affect $30 \%$ of patients, and rejection is the cause of graft loss in $10 \%$ of cases. Chronic rejection is the most common late complication. Cardiovascular diseases are the most common causes of late mortality in pancreas transplantation, so it remains the most effective treatment for type 1 diabetes patients. There is a significant improvement in quality of life and in patient's survival rates. The development of islet transplantation could eliminate or minimize surgical complications and immunosuppression.
\end{abstract}

Keywords: Pancreas transplantation/adverse effects; Immunosuppression; Islets of Langerhans transplantation

\section{RESUMO}

0 transplante de pâncreas é o único tratamento capaz de restabelecer os níveis de glicose e hemoglobina glicada em pacientes diabéticos dependentes de insulina, sem 0 uso de insulina exógena. A evolução do transplante de pâncreas no tratamento de diabetes foi marcada por avanços nos campos da técnica cirúrgica, preservação de órgãos e imunossupressão. A principal complicação da perda do enxerto é a falha técnica, seguida de rejeição aguda ou crônica. Por falha técnica entende-se perda do enxerto dentro dos primeiros três meses seguintes ao transplante devido a: trombose vascular $(50 \%)$, pancreatite $(20 \%)$, infecção $(18 \%)$, fístula $(6,5 \%)$ e hemorragia $(2,4 \%)$. Complicações imunológicas ainda afetam $30 \%$ dos pacientes, e a rejeição causa perda do enxerto em $10 \%$ dos casos. A rejeição crônica é a complicação tardia mais comum. Doenças cardiovasculares são a causa mais frequente de mortalidade tardia no transplante de pâncreas que continua sendo o tratamento mais eficaz para pacientes com diabetes do tipo 1. Há uma importante melhora na qualidade de vida e na sobrevida dos pacientes. 0 desenvolvimento de ilhotas transplantadas pode eliminar ou minimizar complicações cirúrgicas e a imunossupressão.

Descritores: Transplante de pâncreas/efeitos adversos; Imunossupressão; Transplante das ilhotas pancreáticas

\section{INTRODUCTION}

Diabetes mellitus (DM) affects $6 \%$ of the working population. The most common complications are related to vascular, renal and ophthalmologic diseases, and affect $50 \%$ of insulin-dependent diabetic patients within a 20-year $\operatorname{span}^{(1)}$.

Pancreas transplantation (PTx) is the only treatment able to reestablish normal glucose and glycated hemoglobin levels in insulin-dependent diabetic patients without the use of exogenous insulin ${ }^{(2)}$. This can be achieved by transplanting the whole pancreas or by transplant of islet cells, the later still under study. The evolution of PTx in DM treatment has been determined by advances in the fields of surgical technique ${ }^{(3)}$, organ preservation and immunosuppressants ${ }^{(4)}$.

PTx can be performed in three different categories: pancreas transplant alone (PTA), pancreas after kidney transplantation (PAK) or simultaneous pancreas/kidney transplantation (SPK). The most common type is SPK for insulin-dependant DM patients with kidney failure. PAK is performed in patients who were previously submitted to renal transplantation. PTA is performed

\footnotetext{
Post-doctorate degree, Hospital Israelita Albert Einstein - HIAE, São Paulo (SP), Brazil.

${ }^{2} \mathrm{PhD}, \mathrm{MD}$ of Hospital Israelita Albert Einstein - HIAE, Sao Paulo (SP), Brazil.

${ }^{3} \mathrm{MD}$, Irmandade da Santa Casa de Misericórdia de São Paulo, São Paulo (SP), Brazil.

${ }^{4} \mathrm{PhD}, \mathrm{MD}$ of Hospital Israelita Albert Einstein - HIAE, São Paulo (SP), Brazil.

${ }^{5} \mathrm{PhD}, \mathrm{MD}$ of Hospital Israelita Albert Einstein - HIAE, São Paulo (SP), Brazil.

Corresponding author: Ben-Hur Ferraz-Neto - Avenida Albert Einstein, 627 - Office 208 - Bloco A1 - 2nd Floor - Morumbi - CEP $05652-900$ - São Paulo (SP), Brazil - Tel.: 11 3747-3388 -

e-mail: ben-hur@einstein.br

Received on Mar 14, 2010 - Accepted on Sep 01, 2010
} 
in type I DM patient with recurrent non-symptomatic hypoglycemia episodes or hyperlabile $\mathrm{DM}^{(4)}$.

Patients' quality of life improves immensely after PTx. It avoids episodes of hypoglycemia or ketoacidosis, stops daily subcutaneous injections of insulin or frequent punctures to monitor glycemia and change diet restrictions. It also prevents DM complications and protects the transplanted kidney ${ }^{(2)}$.

Regarding secondary DM complications, PTx may lead to partial regression of neuropathy ${ }^{(5)}$, stabilization of retinopathy ${ }^{(6)}$, and regression of the damaged structure of the native kidney in $\mathrm{PTA}^{(7)}$. It may also prevent DM-induced nephropathy in the transplanted kidney in $\mathrm{SPK}^{(8)}$.

There is a theoretical advantage to the islet cell transplantation when compared to the whole organ procedure. However, islet cell transplantation is still an experimental procedure, performed only on clinical studies.

\section{Patient selection}

Patients with DM nephropathy leading to kidney failure are eligible to SPK. Such patients with functioning kidney graft are candidates to PAK. Indeed, these patients are already on immunosuppression and the surgical procedure represents the only risk. PTA is performed in rare occasions, when there is no DMinduced kidney failure, but the clinical control of DM with exogenous insulin is not effective, leading to recurrent acute metabolic complications that require medical treatment, such as asymptomatic hypoglycemia and ketoacidosis ${ }^{(9)}$.

The current patient selection criteria are:

- type 1 DM;

- age between 18 and 55 years;

- absence of systemic DM secondary complications;

- non-renal organic insufficiency;

- no neoplastic disease;

- emotional and social stability;

- no immunosuppression contraindication.

Proliferative retinopathy, iliac arteries obstruction, clinical autonomic neuropathy, HIV-positive and positive T-cell test are relative exclusion criteria.

Absolute exclusion criteria to the procedure are heart failure, severe pulmonary insufficiency, social or emotional instability, active infection or sepsis, neoplastic disease and obesity BMI $>30 \mathrm{~kg} / \mathrm{m}^{2}$.

\section{Donor selection}

Adequate management of possible donors is paramount to avoid graft complications. Hemodynamic and glycemic instability must be avoided.
Selection criteria are not only based on $\mathrm{ABO}$ blood system, but also on negative crossmatching and other criteria, such as age between 10 and 50 years, body mass index (BMI) between 15 and 40 and absence of $\mathrm{DM}^{(10)}$.

The macroscopic evaluation of the pancreas in donor surgery is important and may be the reason to use or not the graft. The surgeon should look closely for signs of pancreatitis, areas of steatonecrosis, excessive glandular edema, hematoma, fat infiltration, and cystic or solid nodular lesions.

Moreover, previous duodenal, pancreatic or spleen surgery, malignancy, infectious diseases (HIV, B or C virus hepatitis and HTLV), chronic hepatic disease and alcoholism must be excluded.

\section{Transplant surgery}

We must bear in mind that the kidney is usually transplanted in the same surgery. The kidney is implanted before the pancreas, because the more delicate organ is less harmed by surgical manipulation. The standard surgical access is throughout an abdominal midline incision. It is preferred to implant the pancreas on the right side as iliac vessels are easily accessed by this side.

The graft blood drainage may be systemic or portal. The first is easily performed but the latter is more physiological, since insulin firstly reaches the liver and only then goes to the systemic circulation. However, glucose metabolism in both techniques is similar and there is no difference in patient and graft survival ${ }^{(11)}$.

The exocrine secretions of the pancreas may drain to the bladder or bowel. In the past, bladder drainage was preferred since graft rejection could be monitored by urinary amylase level. Indeed, most PTx are SPK and rejection episodes are monitored through kidney function. In addition, enteric drainage is more physiologic and has no urinary complications or metabolic complications. Therefore, enteric drainage is now preferred in SPK.

Before the transplant surgery itself, the pancreatic graft is procured en bloc with the spleen, undergoes a back table surgery when a splenectomy and a Y-vascular anastomosis of the superior mesenteric and the splenic arteries are performed with external and internal iliac grafts (Figure 1).

The main surgical steps are summarized below:

1. laparotomy;

2. bladder exposure (only if bladder drainage);

3. terminal ileum and cecum cranial mobilization;

4. iliac vessels dissection and mobilization, with ligature of right iliac internal veins; 


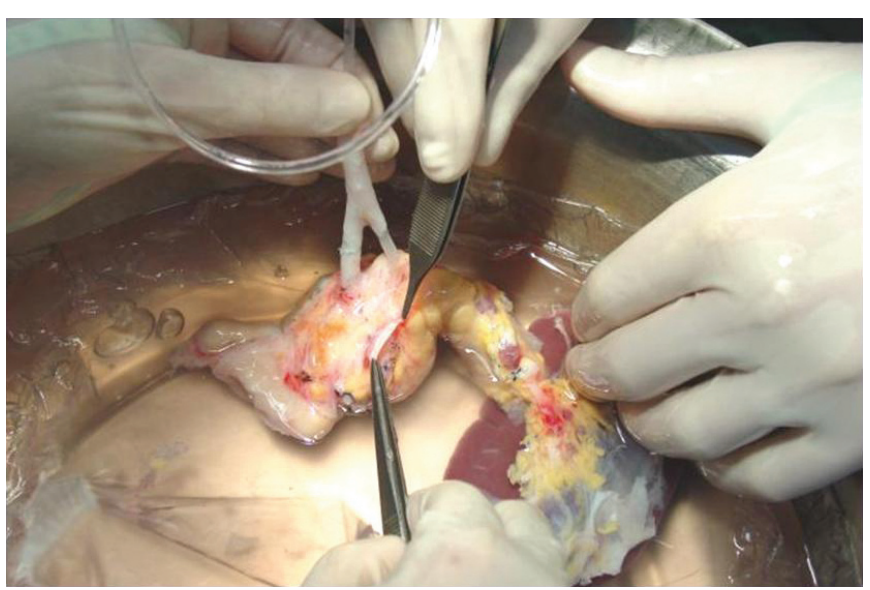

Figure 1. Back-table surgery when a splenectomy and a $Y$ vascular anastomosis of the superior mesenteric and splenic arteries are performed with external and internal iliac graft.

5. graft portal vein termino-lateral anastomosis to the patient's right common iliac vein (systemic drainage);

6. graft artery termino-lateral anastomosis to the patient's right common iliac artery;

7. exocrine graft secretion drainage urinary (laterolateral bladder-duodenum anastomosis) or enteric (latero-lateral ileum-duodenum anastomosis);

8. abdominal cavity hemostasis;

9. abdominal wound closure.

\section{Immunosuppression}

The most frequently used immunosuppressive protocols are based on induction and maintenance phases. Induction drugs are monoclonal antilymphocytes, such as T cell antibodies (OKT3), or polyclonal such as thymoglobulin (ATG); or even anti IL-2 receptor antibodies (basiliximab and daclizumab). Maintenance is based upon the utilization of a calcineurin inhibitor (tacrolimus) associated with anti-metabolic agents (micophenolate mofetil) and corticosteroids (prednisone).

\section{Transplantation results}

According to data from the Organ Procurement and Transplantation Network (OPTN), in the past 21 years (1988 to February 2010) a total of 16,824 SPK and 6,593 PTA + PAK were performed in the United States. The survival rate of SPK patients in the United States is $95 \%$ in the first year, $90.4 \%$ in the first three years and $86.1 \%$ in the first five years. Graft survival rates are of $91.7 \%$, $84.5 \%$ and $76.7 \%$, respectively, for the same periods ${ }^{(12)}$.

The patient and survival rates are lower in the other two PTx types. PTA and PAK have patient survival rates of $94 \%$ in the first year, $89 \%$ in the first three years and
$82 \%$ in the first five years; and graft survival rates of $77 \%$, $63.8 \%$ and $51 \%$ for the same time periods. Male patients show better patient and graft survival rates ${ }^{(12,13)}$.

\section{Complications}

The main complication leading to graft loss is a technical failure followed by acute or chronic rejection. A technical failure is the graft loss within the first three months following transplantation due to vascular thrombosis (50\%), pancreatitis (20\%), infection (18\%), fistula $(6.5 \%)$ and bleeding (2.4\%). In PAK and PTA, patients' rejection is the main cause of graft $\operatorname{loss}^{(14,15)}$.

Intestinal leaks are one of the most serious PTx complications and are found in 5-8\% of patients. It generally occurs immediately after surgery and is related to blood perfusion deficit and ischemia. In most cases, graft removal is the only treatment to this condition $^{(16,17)}$.

Bladder drained PTx, in which exocrinous graft secretions are directed to the bladder, tend to lead to metabolic and urological complications. The most frequent are hematuria, urinary tract infections, urethritis, bladder calculi, and bladder leaks. In such cases, a surgery should be performed to convert the bladder to enteric drainage ${ }^{(15)}$.

Immunological complications still affect $30 \%$ of SPK patients and rejection is still the cause of graft loss in $10 \%$ of cases. The criteria for graft rejection diagnosis are blood creatinine elevation (for SPK), lowering of urinary amylase (for bladder drainage patients), blood lipase elevation, and pancreas biopsy (gold standard) ${ }^{(2)}$.

Infections are still the main cause of death in PTx patients when related to the procedure. They are most commonly bacterial and affect the abdominal wall and the urinary tract. Patients who underwent PTx have a higher risk to develop CMV infection, and it occurs in $25 \%$ of all cases. Fungal infections are difficult to treat and are associated with high death rates. Aspergillus and Criptococcus are the most common agents ${ }^{(18-21)}$.

Neoplasia is a rare complication in PTx. It is more fatal in this procedure when compared to other solid organ transplantation. It is potentially related to immunosuppression and $\mathrm{CMV}^{(22)}$.

Chronic rejection is the most common late complication. Also, cardiovascular diseases are the most common causes of late mortality in PTx.

\section{CONCLUSION}

Pancreas transplantation is still the most effective treatment for type $1 \mathrm{DM}$ patients. There are surgical complications and immunosuppression is mandatory. 
However, based on patient's survival rates following PTx, there is a significant improvement in the quality of life and in kidney failure.

PTA is the appropriate treatment to complicated DM patients without kidney failure and must be performed according to the American Diabetes Society guidelines. The development of islet transplantation could eliminate or minimize surgical complications and immunosuppression.

\section{REFERENCES}

1. LPM. Whole organ pancreas transplant protocol. National Institute of Diabetes and Digestive Kidney Diseases. 1996.

2. Sutherland DE, Gruessner RW, Dunn DL, Matas AJ, Humar A, Kandaswamy R, et al. Lessons learned from more than 1,000 pancreas transplants at a single institution. Ann Surg. 2001;233(4):463-501.

3. David Al, Aquino CG, Guidoni LR, Moricz A, David-Neto E, Pacheco AM Jr, et al. Experimental training model of pancreas transplant. Transplant Proc. 2006;38(6):1941-3.

4. Gruessner AC, Sutherland DE. Pancreas transplant outcomes for United States (US) and non-US cases as reported to the United Network for Organ Sharing (UNOS) and the International Pancreas Transplant Registry (IPTR) as of June 2004. Clin Transplant. 2005;19(4):433-55.

5. Kennedy WR, Navarro X, Goetz FC, Sutherland DE, Najarian JS. Effects of pancreatic transplantation on diabetic neuropathy. $N$ Engl J Med. 1990;322(15):1031-7.

6. Ramsay RC, Goetz FC, Sutherland DE, Mauer SM, Robison LL, Cantrill HL, et al. Progression of diabetic retinopathy after pancreas transplantation for insulindependent diabetes mellitus. N Engl J Med. 1988;318(4):208-14.

7. Fioretto P, Steffes MW, Sutherland DE, Goetz FC, Mauer M. Reversal of lesions of diabetic nephropathy after pancreas transplantation. N Engl J Med. 1998;339(2):69-75.

8. Morel P, Sutherland DE, Almond PS, Stoblen F, Matas AJ, Najarian JS, et al. Assessment of renal function in type I diabetic patients after kidney, pancreas, or combined kidney-pancreas transplantation. Transplantation. 1991;51(6):1184-9.

9. Robertson P, Davis C, Larsen J, Stratta R, Sutherland DE. Pancreas transplantation in type 1 diabetes. Diabetes Care. 2004;27 Suppl 1:S105.
10. Krieger NR, Odorico JS, Heisey DM, D'Alessandro AM, Knechtle SJ, Pirsch JD, et al. Underutilization of pancreas donors. Transplantation. 2003;75(8):1271-6.

11. Katz $H$, Homan M, Velosa J, Robertson P, Rizza R. Effects of pancreas transplantation on postprandial glucose metabolism. $N$ Engl $\mathrm{J}$ Med. 1991;325(18):1278-83.

12.http://optn.transplant.hrsa.gov/ar2009/iKP_Recipients_survival_rate. $h \mathrm{tm} ? \mathrm{o}=4 \& \mathrm{~g}=2 \& \mathrm{c}=13$

13. Tyden G, Bolinder J, Solders G, Brattstrom C, Tibell A, Groth CG. Improved survival in patients with insulin-dependent diabetes mellitus and endstage diabetic nephropathy 10 years after combined pancreas and kidney transplantation. Transplantation. 1999;67(5):645-8.

14. Nath DS, Gruessner A, Kandaswamy R, Gruessner RW, Sutherland DE, Humar A. Late anastomotic leaks in pancreas transplant recipients - clinical characteristics and predisposing factors. Clin Transplant. 2005;19(2):220-4.

15. Sansalone CV, Maione G, Aseni P, Mangoni I, De Roberto A, Soldano S, et al. Surgical complications are the main cause of pancreatic allograft loss in pancreas-kidney transplant recipients. Transplant Proc. 2005;37(6):2651-3.

16. Hanish SI, Petersen RP, Collins BH, Tuttle-Newhall J, Marroquin CE, Kuo PC, et al. Obesity predicts increased overall complications following pancreas transplantation. Transplant Proc. 2005;37(8):3564-6.

17. Corry RJ, Chakrabarti P, Shapiro R, Jordan ML, Scantlebury VP, Vivas CA. Comparison of enteric versus bladder drainage in pancreas transplantation. Transplant Proc. 2001;33(1-2):1647-51.

18. Michalak G, Kwiatkowski A, Bieniasz M, Meszaros J, Czerwinski J, Wszola $M$, et al. Infectious complications after simultaneous pancreas-kidney transplantation. Transplant Proc. 2005;37(8):3560-3.

19. Michalak G, Czerwinski J, Kwiatkowski A, Danielewicz R, Kosieradzki M, Lisik W, et al. Surgical complications observed in simultaneous pancreas-kidney transplantation: thirteen years of experience of one center. Transplant Proc. 2002;34(2):661-2.

20. Stratta RJ, Thacker LR, Sundberg AK. Multivariate analysis of the influence of donor and recipient cytomegalovirus sero-pairing on outcomes in simultaneous kidney-pancreas transplantation: the South-Eastern Organ Procurement Foundation Experience. Transplant Proc. 2005;37(2):1271-3.

21. Stratta RJ. Ganciclovir/acyclovir and fluconazole prophylaxis after simultaneous kidney-pancreas transplantation. Transplant Proc. 1998;30(2):262.

22. Paraskevas S, Coad JE, Gruessner A, Kandaswamy R, Humar A, Sutherland DE, et al. Posttransplant lymphoproliferative disorder in pancreas transplantation: a single-center experience. Transplantation. 2005;80(5):613-22. 